\section{The authors reply}

Os autores respondem

Guimarães et al.
First of all, we wish to thank our Brazilian and international colleagues for their comments. They stress important points in our text and point out some weaknesses as well. In both cases they help make our ideas clearer and offer readers a more complete picture of the process we intended to analyze.

It is extremely important that since 2004 the health research priority agenda has become an essential tool in the Ministry of Health's research policy. From 2004 to late 2006, the Department of Science and Technology (Departamento de Ciência e Tecnologia - DECIT) will have disbursed approximately US\$ 100 million to support research projects, nearly $100 \%$ of which following the priorities set on the agenda. Furthermore, the concern about the importance of such an instrument largely spread across the country and reached a number of State health departments and State research agencies. We believe it is not an overstatement that Brazilian health researchers have now included the Ministry of Health's research policy in their work perspectives.

As Luiz Jacintho da Silva pointed out in his commentary, “...the development of a national policy (or agenda) for health research in Brazil did not begin recently, nor can it be given a date of birth. The Brazilian establishment for research in health-related topics dates back more than a century". This is entirely correct and we view the steps taken since 2003 as part of a long historical process. But we also believe that historical development is not a linear process, and that fast-forwards, slow motion, and even setbacks frequently take place. Our paper merely intends to demonstrate that the Ministry of Health's health research policy achievement in recent years has been a historical milestone. It is true that during the 1980s and 90s a number of initiatives were intended to launch a research policy led by the Ministry of Health. However, various circumstances caused them to fail, and in this sense the DECIT experience since 2003 is quite original. Of course, one could argue that the time elapsed (three years) is too short to assess the results, and as we stated in our paper, the remaining challenge is to make these initial steps permanent and sustainable.

The survey on the financial flows for health research in Brazil, mentioned in the paper, showed a mean annual disbursement of US\$ 573.1 million from 2000 to $2002,72 \%$ of which from the public sector. This is a very reasonable amount of money for a developing country like Brazil. But when we analyze the public share (US\$ 417.3 million) in its major components, nearly $85 \%$ of the investment was for salaries and research fellowships. Only some US\$ 60 million was actually used to support direct research expenditures. This situation led to a Ministry of Health policy decision to not expend money on fellowships and salaries. Research support with DECIT funding has covered only research infrastructure, materials, and services directly linked to research activities and only some few activities involving capacity building like seminars and short-term courses. In fact, the role of DECIT/Ministry of Health in strengthening the Brazilian health research system, as suggested by Sylvia de Haan, has been performed mainly through mobilization of national conferences on science, technology, and innovation in health and setting and constantly updating the research priority agenda. The Brazilian health research support system encompasses several institutional components at the Federal and State levels. At the national level there are three main ministries dealing with health research support: Ministry of Science and Technology, with two agencies, the National Research Council (Conselho Nacional de Desenvolvimento Científico e Tecnológico - CNPq) and the Funding Agency for Studies and Projects (Financiadora de Estudos e Projetos Finep), the Ministry of Education, with one agency, the Coordinating Body for Training University Level Personnel (Coordenação de Aperfeiçoamento de Pessoal de Nível Superior CAPES), and the increasing presence of the Ministry of Health (since 2004). At the State level, there is a series of State funding agencies, normally linked to State departments of science and technology. Capacity building is part of the mission of the Federal CNPq and CAPES agencies, which together have granted some 75 thousand fellowships a year for all research areas combined. Additional funds have been provided by the State agencies. In the last 35 years, Brazil has developed and consolidated strong Master's and PhD programs, now including some 3 thousand courses and 100 thousand students (all research areas combined). These are the main strategies for research capacity building in the country and we believe it would be a 
mistake if the Ministry of Health supported any initiatives that might compete with them.

Eighteen months after the 2nd Conference on Science, Technology, and Innovation in Health, we can view the agenda from a somewhat different perspective. We are not referring to its essential aspects, which were presented and discussed in the article. However, today some other aspects that were unclear at that time (or were not given due importance) can be viewed with different eyes. We believe these aspects deserve being mentioned as "lessons learned".

- Our experience suggests that the agenda setting process is based on "Triple Helix" logic with a permanent compromise among three rationales, namely those of managers/providers, users, and researchers. All of them should be taken into account. It is indisputable that the users' rationale is the most difficult to pinpoint and define. In fact, as Andres de Francisco has pointed out, even a clear definition of the limits of the "users" category is difficult, as is the choice of their representatives. Fortunately, SUS encompasses "social control" mechanisms and layers into its structure, with the National Health Council at the top of the huge pyramid of SUS users' representation. To a certain extent this facilitates the task of listening to users and understanding their rationale. Nevertheless, this remains as a conceptual and practical challenge.

- Towards a fair balance between technical basis and political consensus in setting priorities. When the political consensus is easy, the technical basis will be stronger, and vice versa. However, the goal should be to strengthen both, and at present the more difficult objective is to obtain political consensus.

- It is always desirable to build a health research priority agenda on a solid conceptual and technical basis. In other words, it should have a strong basis in evidence. However, a good technical basis and solid conceptual framework do not always help solve the problem of reaching political consensus. A good technical basis and solid conceptual framework are global matters, while political consensus is a local one. For a given technical basis and conceptual framework (both globally assumed as good), there will be as many roads to consensus as there are countries undergoing the agenda setting process.

- Prioritizing the priorities: the broader the agenda's scope, the looser the definition of priorities. For a specified program, isolated problem, or small geographic region, a priority agenda can be a very simple, self-applicable tool. But when the target is a entire country, particularly a large and diverse one, the strategy becomes more complex. Regardless of the technical and conceptual approaches involved, the agenda takes on huge complexity with numerous potential choices. This issue raises the question of prioritizing the priorities, and leadership by the national health authority is mandatory.

- The health landscape constantly changes, and setting an agenda is thus a process of permanent construction. It can hardly be considered a finished piece of work. 